\title{
MEMÓRIAS RADICAIS PARA A AMÉRICA LATINA CONTEMPORÂNEA. O FUTURO PASSADO DAS ESQUERDAS REVOLUCIONÁRIAS
}

\author{
RADICAL MEMORIES FOR CONTEMPORARY LATIN AMERICA. THE \\ FUTURE PAST OF THE REVOLUTIONARY LEFT
}

Nashla Dahás*

Resumo: O tema central deste artigo é o pensamento político revolucionário na América Latina durante os anos de 1960 e 1970. Especificamente, reconstruímos parte da trajetória da Organização Revolucionária Marxista Politica Operária (ORM-Polop), criada oficialmente no Brasil em janeiro 1961, e do Movimiento de Izquierda Revolucionaria (MIR), criado no Chile cerca de quatro anos depois, ambos situados em contextos democráticos. Discutimos o ineditismo do pensamento político construído pelas organizações, sua defesa de uma revolução socialista latino-americana e a questão da luta armada. Com isso, esperamos contribuir com o debate acerca dos radicalismos; memórias incômodas desde os golpes militares na região.

Palavras-chave: Organização Revolucionária Marxista Política Operária. Movimiento de Izquierda Revolucionaria. Memória política.

\begin{abstract}
The central theme of this article is revolutionary political thought in Latin America during the 1960s and 1970s. Specifically, we reconstructed part of the trajectory of the Revolutionary Marxist Workers' Political Organization (ORM-Polop), officially created in Brazil in January 1961, and the Movement Of the Revolutionary Left (MIR), created in Chile about four years later, both located in democratic contexts. We discuss the novelty of political thought built by organizations, their defense of a Latin American socialist revolution and the issue of armed struggle. With this, we hope to contribute to the debate about radicalisms; Uncomfortable memories since the military coups in the region.
\end{abstract}

Keywords: Marxist Revolutionary Organization Labor Policy. Movimiento de Izquierda Revolucionaria. Political memory.

\footnotetext{
* Nashla Dahás é Pós-doutoranda e professora colaboradora do PPGH-UDESC, sob a supervisão da professora Dra. Mariana Joffily. O estágio pós-doutoral está inserido no PNPD e conta com financiamento da CAPES. Doutora em História pela UFRJ (2015), foi professora substituta no Departamento de História da UFSC entre 2016 e 2017, e pesquisadora da Revista de História da Biblioteca Nacional (RHBN) entre 2011 e 2015. Seus temas gerais de pesquisa são: os sentidos da Revolução na América Latina contemporânea; ditaduras militares e transições democráticas na região.
} 


\section{Introdução}

" Só o que se pode dizer sobre o real é que obviamente não era impossível; nunca podemos provar que era necessário só porque agora é impossível para nós imaginar um estado de coisas em que não houvesse acontecido". (Hannah Arendt, A vida do espírito. 1978)

Em Post-Scriptum (1969), Octavio Paz faz uma revisão de suas reflexões sobre a revolução mexicana analisada em $O$ Labirinto da Solidão (1950). Ali, também aponta caminhos para o destino da América Latina num momento em que, na maioria dos países da região, setores da esquerda consideravam estar vivendo uma situação prérevolucionária, ou algo muito próximo disso.

De fato, entre as décadas de 1960 e 70, as Forças Armadas Revolucionárias da Colômbia (FARC), as Forças Armadas de Libertação Nacional (FALN) na Venezuela, o Exército de Libertação Nacional (ELN) na Bolívia, o Movimento de Libertação Nacional Tupamaros (MLN-Tupamaros) no Uruguai, o Partido revolucionário dos Trabalhadores - Exército Revolucionário do Povo (PRT-ERP) na Argentina, o Movimento de Esquerda Revolucionária (MIR) no Chile, e a Organização Revolucionária Marxista Política Operária (ORM-POLOP) no Brasil, entre outras organizações, discutiam os impasses e as convergências entre as histórias nacionais e a história da região dentro de uma chave revolucionária e socialista.

Em Post-Scriptum, os temas centrais são a questão do desenvolvimento como intimamente ligada à identidade latino-americana, e a capacidade de crítica e de autocrítica política na região. A partir dessas duas questões, apontaremos neste artigo aspectos do pensamento e da ação política da Polop, criada em 1961 no Brasil, e do MIR, criado em 1965 no Chile. Em ambas as organizações, a reflexão sobre o desenvolvimentismo e a crítica à esquerda tradicional foram motores históricos.

\section{Desenvolvimento autóctone}

Foi a partir do contexto pós Segunda Guerra Mundial que o modelo de desenvolvimento europeu e estrangeiro, de maneira geral, passou a ser amplamente questionado na América Latina. Um esgotamento da experiência histórica europeia 
evidenciara-se aos olhos da intelectualidade latino-americana após o alcance da destruição provocada pelo nazismo alemão, e pela possibilidade de fim do mundo trazida pela inserção da bomba atômica como arma de guerra.

Até aquele momento, modernização, desenvolvimento e progresso significavam exclusivamente a capacidade de acúmulo de riquezas, sendo desprestigiadas quaisquer outras formas de experiência. Segundo Paz (1984, p.225), foi exatamente nessa condição de pensamento que mesmo a literatura de esquerda na América Latina incorporou a expressão subdesenvolvimento, elevando-a, inclusive, a um status científico. Com "subdesenvolvimento", se expressava a convicção de que a pluralidade de civilizações e o próprio destino do homem ligavam-se necessariamente a um modelo de sociedade, a sociedade industrial.

Aos poucos, entretanto, os acontecimentos que ficaram conhecidos como 'guerras de libertação' entre as décadas de 1950, 60 e 70, com grande destaque para a revolução cubana em 1959, atingiram profundamente o pensamento latino americano, alterando suas bases teóricas. De acordo com Theotônio dos Santos (2002), economista e ex-militante da ORM-Polop, intelectuais e militantes da região passaram a demonstrar cada vez mais a vontade de mudança, de liberdade econômica, política e intelectual. Segundo o economista, desde meados da década de 1950, organizações como a CEPAL - Comissão econômica para a América Latina e o Caribe -, e a FAO - Organização das Nações Unidas para Agricultura e Alimentação - propunham uma política mundial contra o subdesenvolvimento; e, mais adiante, teses acadêmicas se dedicaram a identificação dos obstáculos nacionais à modernidade alcançada pelos países centrais. Entre as soluções propostas estavam frequentemente mudanças econômicas e comportamentais associadas à máxima produtividade, ao estímulo a formação de poupanças e a criação de investimentos que levassem à acumulação permanente da riqueza dos indivíduos e, em consequência, de cada sociedade. Mas não tardou até que o aprofundamento do sistema capitalista deixasse de ser a única opção viável de transformação sócio-política para as crescentes classes operárias e trabalhadoras na América Latina.

Do ponto de vista específico da influência exercida pela revolução cubana sobre as esquerdas brasileiras, Jean Rodrigues Sales afirma que: 
"De fato, a revolução cubana questionava pelo menos três aspectos da estratégia dos comunistas que estavam cristalizadas entre os dirigentes brasileiros. Primeiro, atualizava a ideia da possibilidade de uma revolução imediatamente socialista no continente, contrária ao caminho proposto pelos partidos comunistas, que era o de uma revolução feita em duas etapas. Em segundo lugar, a guerrilha vitoriosa em Cuba colocava em xeque a ideia de que a revolução no continente latino-americano seria pacífica, como há muitos anos apregoavam os partidos comunistas (PC's). Enfim, o fato de a revolução cubana ter sido liderada pelo grupo 26 de Julho levou muitos militantes a questionarem o papel de vanguarda dos PC's no processo revolucionário". (SALES, 2005).

Assim, tanto do ponto de vista do pensamento latino-americano sobre sua posição na geopolítica mundial, quanto em termos de conjunturas nacionais com seus problemas históricos de desigualdade social, a liberdade e as formas de libertação tornaram-se pautas irreversíveis nas agendas esquerdistas. Em A Utopia Fragmentada, a historiadora Maria Paula Araújo (2000) mostra como no Brasil as esquerdas tomaram para si a tarefa de interpretar aquela conturbada realidade produzindo espécies de diagnósticos e de prognósticos para o país:

"A compreensão da realidade brasileira, a definição do caráter da revolução que lhe era apropriado, a especificidade de sua inserção no capitalismo internacional, a singularidade de suas relações de classe, bem como o tipo de luta de classes que daí decorreria, a definição do caráter da ditadura militar (se estrutural ou conjuntural) e a análise da trajetória histórica que levara o país até ela (o que muitas vezes implicava violentos processos de crítica e autocrítica entre as diferentes correntes), eram pontos que mobilizavam militantes, simpatizantes e intelectuais vinculados, de alguma forma, aos partidos e organizações de esquerda". (ARAÚJO, 2000, p.83).

A Polop se insere nesse contexto e é um exemplo radical no qual a revisão da história política recente do país justificou quase automaticamente a defesa da revolução socialista imediata. O Partido Comunista do Brasil (PCdoB), criado em fevereiro de 1962, e a Ação Popular (AP), fundada em junho do mesmo ano, integraram também militantes dissidentes do PCB ou independentes dele, que contribuíram para a construção de alternativas de esquerda antes do golpe civil-militar. Apesar disso, até aquele momento, as linguagens, a memória, as estratégias de ação política e o imaginário ligado às esquerdas eram ainda profundamente vinculados ao Partido Comunista Brasileiro (PCB), fundado em 1922 sob a influência da Revolução Russa de 
1917, e de orientação ideológica alinhada a Moscou. Durante pelo menos três décadas, a União Soviética foi o modelo dominante para as esquerdas brasileiras, assim como o PCB foi o único partido comunista a disputar legalmente o apoio popular. Em seu trabalho sobre o século XX francês, Jean-François Sirinelli (2014) afirma que mesmo na Europa, até meados dos anos 1950, a União Soviética era a peça chave de uma visão binária da História, fortemente impregnada de marxismo-leninismo, com uma classe exploradora a abater - a burguesia -, e uma classe explorada a promover - o proletariado, justamente a classe alavanca das revoluções por vir.

De acordo com Sirinelli, em poucos anos, porém, houve uma dupla transferência, ao mesmo tempo semântica e geográfica, que deslocou o papel da revolução para o terceiro mundo e o modelo revolucionário da União Soviética para China ou Cuba:

\begin{abstract}
"Depois das decepções a respeito da União Soviética em 1956 relatório Krusvhev em fevereiro, repressão na Hungria no outono -, depois da constatação de que a classe operária ocidental, longe de se tornar o estopim esperado, também se beneficiava do enriquecimento dos Trinta Gloriosos e já quase não aspirava a uma ruptura revolucionária, outro binômio vai assumir o papel de suposto motor da História: o par imperialismo - Terceiro Mundo. De fato, é a visão de uma luta de classes dilatada à escala planetária que substitui a precedente: a exploração teria se tornado progressivamente mundial, e são os jovens Estados em formação naquele momento, vitimas de tal exploração, que se tornariam a ponta de lança das revoluções por vir. O novo binômio se encarna, portanto, em alguns desses Estados, e às transferências semânticas, se acrescenta um deslizamento geográfico: o modelo declinante da União Soviética é substituído especialmente por aqueles da China ou de Cuba". (SIRINELLI, 2014, p. 56).
\end{abstract}

A subordinação do $\mathrm{PCB}$ às decisões teóricas e práticas do Comitê Central do Partido Comunista da União Soviética consistiu exatamente na primeira grande crítica da Polop no campo das esquerdas brasileiras no começo dos anos 60. Em artigo publicado na Revista de História da Biblioteca Nacional, Apolo Heringer Lisboa, exmilitante da Polop, afirma que essa situação de subordinação inibiu o desenvolvimento de uma elite intelectual brasileira na política e nos movimentos sociais, ao longo das décadas em que o Partido foi hegemônico e teve grande influência nas fábricas e 
universidades, nos meios intelectuais e artísticos. Segundo Heringer, o PCB cresceu profundamente carente de autonomia política e intelectual (LISBOA, 2013, pp. 31-33).

Em grande medida, do binômio "Imperialismo - Terceiro Mundo", citado por Sirinelli, resultará, na América Latina, a formação de uma esquerda radical profundamente crítica aos PCs e em defesa da ação política imediata. No Brasil e no Chile, a Polop e o MIR foram organizações emblemáticas desse fenômeno latino americano.

Polop e MIR consideraram que era preciso romper com os dogmatismos políticos, buscando nas especificidades da história nacional as possibilidades mais adequadas para o enfrentamento politico e para a revolução socialista. Ambas as organizações interpretaram o contexto internacional - embates anticoloniais na África e na Ásia, os movimentos nacionalistas bascos e irlandeses na Europa, e, principalmente, a Revolução Cubana em 1959, entre outros acontecimentos -, a partir da tese do esgotamento do ciclo de expansão e desenvolvimento capitalista iniciado por volta da década de 1930.

Em artigo sobre a questão do desenvolvimento e da dependência no pensamento marxista, Claudia Wasserman (2009) afirma que entre os anos 1950 e 1970, destacou-se nas ciências sociais latino-americanas a temática central do desenvolvimento, que terminou por organizar toda a reflexão teórica da região e orientou um conjunto de investigações científicas. De acordo com a historiadora, em países como Brasil, Chile, Argentina e México, desde os anos de 1930, a estrutura social começou a dar espaço a uma burguesia industrial nascente que, embora débil, projetou a industrialização como ponta de lança para um projeto de desenvolvimento econômico. No entanto, a partir da década de 1960, essas políticas que combinavam industrialização, urbanização e desenvolvimento foram profundamente questionadas pelo pensamento de esquerda. A dificuldade de viabilizar as chamadas "reformas estruturais" que previam a ampliação da participação política e a redução das desigualdades sociais, além da eclosão da revolução cubana, levaram alguns grupos à busca de alternativas de "desenvolvimento autônomo".

Tanto na Polop, quanto no pensamento mirista se destacam as críticas às teorias da industrialização como propulsoras do desenvolvimento, que passaram a ser associadas à burguesia. Por outro lado, as duas organizações também vão criticar 
duramente os partidos comunistas identificados com um marxismo tradicional que interpretava a sociedade latino-americana a partir de uma leitura etapista e linear dos modos de produção, e, sobretudo, que postulava a aliança entre os PCs e as organizações burguesas.

Segundo Santos (2000), no caso brasileiro, essa revisão crítica do conceito de desenvolvimento feita por intelectuais de algumas organizações da esquerda radical evidenciou os limites históricos da proposta nacional e democrática que inspirou a Revolução de 1930, os últimos anos do Estado Novo (1943-45), o segundo governo Vargas (1950-54), uma ala do governo Kubitschek (1955-60) e o governo João Goulart (1961-64). Ruy Mauro Marini, Theotônio dos Santos e Vânia Bambirra são alguns dos principais intelectuais da Polop a elaborar uma proposta de desenvolvimento autônomo chamada Teoria da Dependência.

O desdobramento dessas reflexões levou a Polop ao pioneirismo na América Latina na construção de uma interpretação marxista do processo histórico que caracterizava a revolução como, simultaneamente, antiimperialista e socialista, rechaçando a ideia do predomínio de relações feudais no campo e negando à burguesia latino-americana a capacidade para dirigir a luta antiimperialista.

No caso do Chile, desde seu surgimento em 1965, o MIR rompe com a historiografia marxista clássica no país, que partia de um Chile feudal, e que, portanto, apontava inicialmente para a necessidade de desenvolvimento etapista do capitalismo a criar as contradições e condições objetivas necessárias para fazer a revolução.

Ao longo de sua trajetória, o MIR defendeu o combate "a toda concepção que acolha ilusões na burguesia progressista e que pratique a colaboração de classes"1, opondo-se claramente a certa combinação entre ideologia política e modelo econômico que encontrou abrigo nas propostas desenvolvimentistas e comunistas dos anos 1960.

\section{A crítica como fundamento da união continental}

\footnotetext{
${ }^{1}$ Declaração de Princípios do Movimento de Esquerda Revolucionária no Chile, 1965. CEME - Chile. Disponível em http://www.archivochile.com/Archivo_Mir/Doc_Agosto_65_a_67/miragosto65a670001.pdf (Último acesso em janeiro de 2015)
} 
Uma identidade imaginária ligada à história colonial e à cultura latina foi levada a sério por organizações da esquerda radical latino americana nos anos 1960 e 70. Preocupados em destacar a zona de interseção entre os problemas sociais, os sentimentos coloniais e um republicanismo incipiente, militantes e intelectuais dessas organizações construíram uma versão revolucionária para a história da região. No Brasil e no Chile, especialmente, essa experiência política radical foi apontada como semelhante entre um e outro país por seus próprios agentes históricos.

Claudia Wasserman (2012), de certo modo, explica o surgimento desse pensamento americanista entre a esquerda radical, sobretudo, em razão do impacto provocado pelos acontecimentos em Cuba, segundo ela, muito maior do que aquele causado pela Revolução Russa sobre a Europa. A historiadora afirma que todos os aspectos dessas sociedades foram atingidos, desde a extrema direita, a economia e as relações internacionais, até as alterações na vida cotidiana exemplificada pelo surgimento de novos termos como "cubanizar".

De fato, o que se pode observar a partir dos documentos políticos de Polop e MIR é que grande parte da esquerda autodenominada radical entre os anos 1960 e 70 enxergou um conjunto de condições sociais homogêneas entre os países da região. Nesse processo simultâneo de elaboração intelectual e ação política, a história comum da formação social das nações latinas tornou-se o ponto central para o esforço de construção de uma narrativa histórica identitária que se pretendia inédita na maioria dos países. Ela começava com a inserção das colônias ibero-espanholas na dinâmica de funcionamento do capitalismo comercial europeu, e terminava com a Revolução socialista na América Latina.

Em 1965, a divulgação da Declaração de Princípios do Movimiento de Izquierda Revolucionaria no Chile expressou uma leitura do contexto nacional e internacional, que desde o início da década de 1960, e durante as décadas seguintes, marcou a prática e o pensamento das esquerdas radicais. Iniciado com a imagem de Lênin, o documento datilografado é um pré-Programa, uma espécie de texto inicial que deveria servir como fonte para a elaboração do futuro Programa do "Partido da Revolução" no Chile:

"O mundo atual está dividido em países de organização econômica social capitalista (entre os quais há países opressores e oprimidos) e 
nações de estrutura socialista que, pela primeira vez na história estão alcançando força suficiente para decidir em grande medida o curso dos acontecimentos internacionais. Por graves que sejam os erros que só podem ocorrer nas burocracias políticas que dirigem os estados socialistas, o MIR proclama claramente o seu apoio ao campo socialista e rechaça categoricamente a ideia de uma possível neutralidade frente ao choque de ambos os setores. Os países socialistas não podem ser qualificados como imperialistas quando estendem suas ações para fora de suas fronteiras. Somente através da cooperação mundial dos trabalhadores que promovem a revolução em cada um dos países não socialistas poderá conquistar-se a paz. A coexistência pacífica, ativa ou passiva, representa um acordo provisional entre as burocracias socialistas e o imperialismo destinado a retardar ou impedir essas revoluções e, na mesma medida, conserva a injustiça social em grandes regiões do planeta, mantendo latentes as causas da guerra. [...] O MIR se pronuncia decididamente em favor da revolução nos países coloniais e semicoloniais, e de toda a luta antiimperialista; apoia as guerras revolucionárias de libertação que levam adiante os povos oprimidos. [...] O MIR proclama o seu apoio a Revolução cubana por entender que seus métodos de luta insurrecional, liquidação da oligarquia e burguesia nacionais, atitude anti-imperialista e formas de construção do socialismo, incluindo seus propósitos de não permitir o sectarismo, nem o burocratismo, constituem um exemplo para a conduta dos revolucionários do continente. O MIR lutará pela organização das Repúblicas Unidas Socialistas da América Latina, unidade que concebemos, não como um só país, mas como Unidade Federativa das Nações Latino Americanas sob o regime socialista $\mathrm{e}$, por consequência, não aceitamos a unidade da América Latina sob a direção das burguesias nacionais e do imperialismo estrangeiro". (Declaração de Princípios. MIR, 1965) $)^{2}$

O projeto de construção de uma "Unidade Federativa das Nações Latino Americanas sob o regime socialista" levou o MIR a criar, de fato, ramificações radicais no Brasil, na Colômbia, Venezuela, na Bolívia e no Peru (VITALE, 1999). Vale dizer que a denominação Movimiento de Izquierda Revolucionaria não é originalmente chilena, mas argentina, criada por Sílvio Frondizi, irmão do ex-presidente argentino Arturo Frondizi, e que fundou a organização Praxis y Movimiento de Izquierda Revolucionaria (MIR-Praxis), em 1961. Silvio Frondizi adquiriu projeção continental naqueles anos como fundador do primeiro MIR latino-americano, mas não prosseguiu como guia teórico dessas organizações. Segundo Samuel Amaral (2015), em seu estudo

\footnotetext{
${ }^{2}$ Declaração de Princípios do Movimento de Esquerda Revolucionária no Chile, 1965. CEME - Chile. Disponível em http://www.archivochile.com/Archivo_Mir/Doc_Agosto_65_a_67/miragosto65a670001.pdf (Último acesso em janeiro de 2015)
} 
sobre a contribuição de Frondizi para o surgimento das esquerdas radicais na América Latina, o papel do argentino foi mais de "parteiro", do que de inspiração intelectual.

Em 1965, a interpretação histórica da realidade chilena e a identificação de elementos históricos comuns a América Latina foram utilizados como argumentos para a defesa da revolução socialista nas sociedades subdesenvolvidas, assim como para a defesa da integração latino-americana como condição absoluta para o êxito das revoluções nacionais.

Os acontecimentos vizinhos foram muito recorrentes nas publicações mensais das organizações radicais. Sabe-se hoje que as revistas, periódicos e as declarações públicas das diferentes organizações radicais circularam de forma legal ou clandestina como forma de resistência intelectual em quase todos os países, com destaque para o $E l$ Rebelde $^{3}$, órgão oficial do MIR chileno, o Correo de La Resistencia ${ }^{4}$, órgão criado pelos miristas no exílio e cujos editoriais tiveram frequentes contribuições de Ruy Mauro Marini. A Revista Punto Final ${ }^{5}$, e a Estratégia, acompanharam desde 1965 os acontecimentos mais marcantes na América Latina, assim como a Política Operária ${ }^{6}$ editada no Brasil entre 1962 e 64, e no exterior pelos militantes exilados, impressa onde fosse possível. Na Argentina, por exemplo, a criação do órgão El combatente em 1968 pelo Partido Revolucionário dos Trabalhadores - $\mathrm{PRT}^{7}$ imprimiu e distribuiu clandestinamente mais de 15 mil exemplares semanais até o começo de 1976, quando um novo golpe de Estado tomou conta do país. Na verdade, são muitos os exemplos desse intercâmbio entre as propostas de Revolução Socialista adequadas a situações nacionais distintas, motivadas, porém, por razões e contextos apontados como semelhantes.

\footnotetext{
${ }^{3}$ Todas as edições do periódico a partir de 1970 estão digitalizadas na íntegra e são acessíveis através do site: http://www.archivochile.com/entrada.html

${ }^{4}$ A maior parte dos editoriais escritos por Ruy Mauro Marini pode ser encontradas no site: http://www.marini-escritos.unam.mx/index.htm

5 Todas as edições da Revista Punto Final podem ser acessadas através do site http://www.puntofinal.cl/

${ }^{6}$ A Revista está em processo de digitalização e alguns de seus números já podem ser consultados através do site: http://www.centrovictormeyer.org.br/

${ }^{7} \mathrm{O}$ site atual do PRT -

http://www.prtargentina.org.ar/documentos/partido/causas_de_la_derrota_del_prt.html - está ainda em construção, mas oferece bom panorama da história do partido e de seus objetivos nas décadas de 60 e 70 do século XX.
} 
Em junho de 1967, o Documento $\mathrm{N}^{\circ} 1^{8}$ do Movimiento de Liberacion NacionalTUPAMAROS (MLN-T) do Uruguai ${ }^{9}$ enumerou aqueles que seriam os elementos essenciais da continentalidade da Revolução Socialista:

“1. É um direito e um dever que as organizações revolucionárias colaborem com suas máximas possibilidades na construção e elaboração da estratégia continental. [...] 4. América Latina, e, portanto, nosso país, consistem em parte do sistema imperialista mundial. Sua libertação, então, depende da derrota em escala continental do imperialismo. [...] 8. Enquanto não se modificar esta situação, é impossível pensar na libertação em termos nacionais, independentemente do resto da América Latina. [...] 11. Temos que fazer frente ao imperialismo por meio de uma guerra de desgaste na América Latina. Transformar cada palmo em um terreno de luta, em uma zona que lhes seja hostil, "criar vários Vietnãs na América". [...] 12.É correto orquestrar uma estratégia continental que racionalize a aplicação das forças e recursos onde melhores resultados ela poderá encontrar. [...] 15.Subscrevemos em todos os seus termos o último documento de Guevara. [...]". (MLN-T, 1967).

O MNL-Tupamaros tornou-se mais conhecido no circuito radical latino americano após o sequestro e o assassinato do representante da Seção de Segurança Pública da USAID - United States Agency for International Development -, Dan Mitrione, em 1970. A sigla USAID já era famosa entre os brasileiros desde o golpe de $1964^{10}$, quando os acordos com a Agência no campo da educação (acordos MECUSAID) foram motivo de protestos não apenas de guerrilheiros, mas de grupos nacionalistas e anti-imperialistas de maneira geral. Como afirma o historiador Rodrigo Patto Sá Motta (2004), a ação dos Tupamaros teve grande impacto sobre o Brasil e trouxe ao centro das discussões a intervenção dos Estados Unidos a partir da inserção e do aparelhamento militar e intelectual das polícias do terceiro mundo.

Em exílio no México em 1984, Ruy Mauro Marini afirmou que o MNL foi uma das organizações revolucionárias mais importantes da América Latina, e destacou as reflexões de seu fundador Raúl Sendic. No artigo intitulado Comentario a Raúl Sendic (1984), Marini ressaltou que, embora o líder Tupamaro não tenha estudado economia de

\footnotetext{
${ }^{8} \mathrm{O}$ documento pode ser lido na íntegra em: http://www.archivochile.com/America_latina/JCR/MLN_T/tupa_de/tupade0001.pdf (último acesso em fevereiro de 2012)

${ }^{9}$ Documento acessivel em: http://www.archivo-chile.com

${ }^{10}$ As relações entre a ditadura brasileira e assuntos internos de países vizinhos são descritas de forma mais aprofundada em Silva, 2010.
} 
uma perspectiva acadêmica ou técnica, Sendic compreendeu perfeitamente o papel determinante do elemento econômico no destino dos homens. Colocou no centro de suas reflexões teóricas a economia no processo de transição socialista, e tomou como pontos de referência a Polônia, Cuba e Nicarágua, em suas críticas sobre a economia capitalista, e mais especificamente, sobre a economia capitalista dependente.

Deste mesmo ponto de vista econômico, Ruy Mauro Marini também analisou os casos de Brasil e Chile destacando suas semelhanças. Em El reformismo y la contrarrevolución, (1976), o ex-militante da Polop afirma que as circunstâncias da economia chilena nos anos 60 não eram particulares daquele país, mas haviam já se configurado antes em países latino americanos de maior desenvolvimento econômico como Brasil e Argentina, onde o crescimento da burguesia gerou a necessidade desta classe de mudar estruturalmente o aparato produtivo em favor do grande capital nacional associado e internacional. Estes, por sua vez, se viram privados de maiores volumes de acumulação por políticas econômicas ligadas a um estágio de desenvolvimento das forças produtivas mais voltado para o campo e para o nacionalismo econômico do pós-guerra. Dessa forma, o confronto de interesses entre o grande capital e as classes trabalhadoras se tornou, em médio prazo, comum aos países latino-americanos.

Ruy Mauro Marini chamou especial atenção para a brutalidade com que esse confronto ocorreu no Chile; resultado em parte da grave crise social, da radicalização política e do enfraquecimento das direitas verificado com a vitória de Salvador Allende à presidência da República em 1970 - por sua vez, outro dinamizador das propostas americanistas radicais.

Um ano após a chegada de Allende ao poder pela via eleitoral, Éder Sader, fundador da Polop e dirigente da organização entre 1962 até a instituição do AI-5 no Brasil em 1968, publicou artigo intitulado O Chile entre a legalidade burguesa e a Revolução ${ }^{11}$. Sader caracteriza a coalizão de Allende, a Unidade Popular, como: "um governo de esquerda, vitorioso nas eleições, que se propõe a construir as bases para o socialismo respeitando as regras da legalidade burguesa". A UP é descrita como

${ }^{11}$ O artigo circulou inicialmente no Brasil em edição mimeografada datada de 1971, logo após a posse de Salvador Allende. Foi traduzido para o francês (Lês Temps Modernes No 310, maio de 1972, Paris) e para o alemão (Probleme des Klassenkampfes №. 3, maio de 1972) e pode ser encontrado na íntegra em http://www.centrovictormeyer.org.br/ (Último acesso em fevereiro de 2015) 
"esdrúxula e desconcertante" para as esquerdas revolucionárias, pois rompeu com as experiências comuns na América Latina "de tentativas de governos reformistas burgueses". Ao mesmo tempo, a UP era, efetivamente, um governo "sustentado pelas organizações sindicais e políticas do proletariado".

Em tais termos, Eder Sader deixou claro o radicalismo que unia os grupos de esquerda revolucionária no continente contra a estratégia eleitoral de chegada ao poder. Além disso, demarcou um impasse próprio aos contextos de Brasil e Chile: a defesa radical da Revolução socialista imediata contra governos de esquerda que conquistaram pacificamente o controle do Estado.

Na Argentina, no Paraguai e na Bolívia, também encontramos entre as esquerdas radicais a valorização da constituição de um partido de vanguarda que guiasse a população insatisfeita como alternativa revolucionária no seio das esquerdas tradicionais ${ }^{12}$. De modo geral, não se tratava de um enfrentamento das injustiças sociais, da desigualdade de terras e rendas, de muitos problemas que ainda hoje rondam as sociedades latino-americanas, e para os quais ainda se propõe antigas soluções, tais como a melhoria da qualidade da educação pública ou o aumento do salário mínimo. Tratava-se de buscar em um terreno inexplorado da experiência política novas referências para a vida em sociedade. Da Europa, as organizações radicais frequentemente propunham a incorporação de um legado revolucionário marxista leninista, e nada mais. Aos Estados Unidos dirigiam todo o ódio anti-imperialista acumulado durante séculos de construção de uma história de exploração e dominação colonialista. O esforço notório em busca de autonomia intelectual, partidária e social as unia em torno de um pensamento americanista.

Narrativas sobre o passado de experiências históricas comuns ligadas à colonização e ao subdesenvolvimento desdobravam-se, muitas vezes, em uma grande expectativa sobre a capacidade de determinação do futuro que esses estudos poderiam fornecer, além do ineditismo da experiência que se procurava alcançar. A despeito de todas as especificidades e das diferenças dos processos nacionais, uma conjuntura comum marcou a politica de uma esquerda intelectualizada e radical na América Latina,

${ }^{12}$ Sobre o processo paraguaio ver Miranda (s/d). No caso da Bolívia, as Tesis de Pulacayo defendidas pelo Partido Obrero Revolucionário - POR, podem ser encontradas na íntegra em http://pulacayo.blogcindario.com/2006/05/00004-la-tesis-de-pulacayo.html (Último acesso em junho de 2013) 
que se mostrava atenta ao governo do general Lázaro Cárdenas no México (1934-40), ao peronismo argentino (1945-56), a revolução boliviana (1952-64) dirigida pelo MNR, e ao regime reformista na Guatemala (1944-54), derrubado pela Cia.

Nos casos de Brasil e Chile, uma crítica comum às esquerdas tradicionais aliouse a uma expectativa de americanismo radical compartilhada desde o começo dos anos 60. Há, sem dúvida, nas publicações radicais de Brasil e Chile uma expectativa de união diante de um inimigo "imperialista" comum, os Estados Unidos. Além disso, a experiência cubana aparece como modelo inquestionável nos dois casos, inclusive no que diz respeito à tessitura de críticas à exportação e implantação inflexível do modelo de guerrilha castrista no resto das Américas.

Contudo, não observamos a construção de um pensamento americanista como caminho epistemológico, de fato, independente. O passado comum consiste em um legado de desigualdade e de injustiças sociais profundas herdados do colonialismo e, em seguida, do imperialismo, cujo ciclo se deseja romper. A união das forças radicais é sempre o meio para o alcance de interesses nacionais considerados maiores. Nunca é vista como um fim em si mesmo, a partir do qual novas maneiras de viver, talvez, mais próximas de um suposto regime socialista, pudessem ser criadas e imaginadas também como resultado de experiências coloniais e imperialistas. Mas o modelo de desenvolvimento industrial e todo o seu léxico simbolizado pela dicotomia "países desenvolvidos e subdesenvolvidos", criados sob o sistema capitalista de divisão do trabalho e de papeis sociais é mantido nas interpretações revolucionárias, especialmente, nos casos de Polop e MIR.

\section{Brasil e Chile}

Polop e MIR Foram críticos das esquerdas "tradicionais" que de forma inédita nos dois países chegaram ao mais alto cargo do poder executivo. Seus líderes, João Goulart no Brasil, no começo da década de 60, e Salvador Allende no Chile, cerca de 10 anos depois, conquistaram altos índices de popularidade e apresentaram projetos de mudança cujo tema mais latente era a justiça social. A proposta chilena tornou-se a primeira tentativa de transição constitucional para um "socialismo democrático". 
Ainda que em graus muito diferentes, João Goulart e Salvador Allende apresentaram propostas de alteração das continuidades que haviam marcado o quadro político e social vigente nos dois países. Não por acaso, as reformas na estrutura fundiária - reforma agrária -, no sistema eleitoral - inclusão das parcelas excluídas como analfabetos e baixos postos militares -, e na Constituição Federal, ressaltando-se, no caso chileno, o socialismo como regime político constitucional, foram os temas que provocaram maior radicalização ideológica e polarização social.

Os dois governos experimentaram naquele momento um fenômeno comum aos países cuja industrialização/urbanização foi alavancada pela e após a Segunda Guerra mundial. Foram tempos de imprevisibilidade, marcados pelas possibilidades abertas ao futuro nacional e transformadoras em relação à história oficial dos dois países. A participação da sociedade civil, organizada em movimentos políticos sociais urbanos e rurais, o engajamento da grande imprensa, agora munida de importantes reformas técnicas no campo da propaganda - difundidas pelos EUA desde a década de 1950 -, e o protagonismo dos militares na cena política, deram o tom de um debate político público, amplo e acirrado.

A fragilidade mais clara desses governos residia nas dificuldades de conquistar maioria no Congresso Nacional. João Goulart não foi eleito, mas chegou à presidência após a renúncia do vice Jânio Quadros, num tempo em que os dois cargos do executivo não precisavam ser compostos por políticos da mesma coligação. Jânio integrava a UDN (União Democrática Nacional), partido identificado com a direita mais claramente de direita que o Brasil republicano já teve. Goulart era visto como o herdeiro político de Getúlio Vargas e era líder do Partido Trabalhista Brasileiro (PTB), de projeção nacional. Seus discursos repetiam a ideia de um "Brasil voltado para o desenvolvimento com igualdade social".

Salvador Allende seguiu o caminho tradicional e constitucional de chegada ao poder. Havia sido candidato à presidência em outras três eleições antes de 1970, ano em que venceu com apenas 36\% dos votos, contra 35\% de Jorge Alessandri, e 28\% de Ramiro Tomic. Allende estava à frente da UP (Unidade Popular - coalizão de partidos que incluía o Partido Socialista e o Partido Comunista chileno) e esforçava-se por tecer acordos com o PDC (Partido Democrata Cristão). Este último havia sido formado em 1957 por dissidentes de partidos conservadores. 
Até este momento, o Chile havia oscilado entre a larga tradição democráticoliberal - pioneira na América Latina no que se refere à formação de um sistema parlamentar representativo, e à instituição do voto secreto vigente desde 1874 -, e a violência do terrorismo de Estado, praticado de maneira sistemática quando as bases do Estado Nacional estavam ameaçadas; quais sejam, a estrutura fundiária, o Exército e a Igreja. Na década de 1930, por exemplo, a pena capital por fuzilamento foi reservada aos envolvidos em assassinatos e motins militares. As Forças Armadas chilenas foram as primeiras latino-americanas a receberem treinamento militar de missões estrangeiras e orientadas pelo Exército Alemão, depois da unificação da Alemanha, e pela Royal Navy Britânica, no início do século XX.

Tanto o governo da UP, quanto o Trabalhista de Goulart, se tornaram alvos de estratégias de desestabilização apoiadas e financiadas por diferentes setores de oposição. Eles contavam com o apoio norte-americano incisivo em tempos de Guerra Fria.

Muitos acusados de subversão pela ditadura instaurada em 1964 no Brasil foram exilados ou fugiram do país especialmente em direção ao Chile que, em 1970, acabava de eleger Salvador Allende ${ }^{13}$. Sobre esse assunto, a historiadora Denise Rollemberg (1999) demostrou uma diferença importante entre as duas gerações de exilados brasileiros. A primeira geração teria ocorrido imediatamente após o golpe, e os militantes e políticos teriam se dirigido majoritariamente para o Uruguai. A segunda leva de exilados teria acompanhado o endurecimento da repressão em 1968, responsável pelo "golpe final" nas lideranças esquerdistas. Desta vez o destino dos militantes foi o Chile, onde muitos teriam encontrado novas razões para viver e para acreditar na revolução socialista. Durou pouco tempo, como se sabe. Mas da experiência resultaram as colônias internacionais de solidariedade aos chilenos. Leopoldo Montenegro, exmilitante do MIR e atualmente responsável pela coordenação do Espaço de Memória Londres $38^{14}$ no Chile, afirma aos visitantes do ex-centro de repressão e extermínio da ditadura pinochetista que os brasileiros são como camaleões, possuem essa imensa capacidade de integrar-se às mais diferentes culturais locais e de lutar tão

\footnotetext{
${ }^{13}$ Para uma trajetória dos exilados brasileiros no Chile ver: MARQUES, 2011.

${ }^{14}$ http://www.londres38.cl/1937/w3-channel.html O site disponibiliza informações sobre a história do local, análises históricas sobre o tema e documentos digitalizados sobre o funcionamento do aparato repressivo chileno.
} 
apaixonadamente quanto como se estivessem em seu país de origem. "Foi assim com Eder Sader, Marco Aurélio Garcia e Ruy Mauro Marini, até os anos de 1980, quando surgiu o PT, entre outras razões", observa Montenegro.

Em 11 de setembro de 1973, o Palácio La Moneda no Chile foi bombardeado com o presidente Salvador Allende em seu interior de capacete militar e arma em punho. Golpes e tentativas de golpe militares já haviam ocorrido em 1952 na Bolívia, um ano depois na Colômbia, em 54 no Paraguai e na Guatemala, em 1962 e 68 no Peru, em Honduras em 1963, no Brasil em 64, no Equador em 1972 e no Uruguai em junho de 1973.

Pouco menos de dez anos antes do 11 de setembro chileno, o presidente João Goulart optou pelo exílio à resistência em nome da "segurança da população brasileira", conforme aponta Jorge Ferreira (2011). Ele morreria antes que pudesse pisar novamente no Brasil. O golpe deflagrado pelos militares com amplo apoio civil ocorreu de maneira menos violenta do que no Chile, ou, ao menos, com menos resistência.

Durante todo o seu governo, entre 1961 e 64, João Goulart se deparou com limitações constitucionais às reformas que propunha, e se esforçou para costurar complicados acordos parlamentares para aprovação de algumas medidas. Interpretações recentes como a do historiador Jorge Ferreira (2015) consideram o chamado Comício da Central, cerca de quinze dias antes do golpe, como o acontecimento mais emblemático da radicalização do governo, ponto de inflexão do presidente no sentido de uma escolha por esta via de ação política. O golpe ocorreu antes que medidas efetivas fossem realizadas.

Salvador Allende por sua vez, concretizou grandes transformações no Chile como a rápida estatização da economia, e a instauração da participação dos trabalhadores em todos os âmbitos da sociedade, mediante um acordo com a CUT. Destacam-se, nesse sentido, os Cordões Industriais, experiência de territorialização e integração de indústrias de vários ramos produtivos formando literalmente um cordão.

Em agosto de 1973, Eder Sader, militante da Polop exilado em Concepción, escreveu ensaio para a revista Marxisme et Révolution em que analisou a formação do Cordón Cerrillos, “o primeiro Cordón da mais importante região industrial chilena”. A experiência foi tomada como exemplo da capacidade de organização popular para transformação de qualquer institucionalidade política, inclusive daquela que estabelecia 
marcos reais inéditos de uma via legalista para a viabilização do Socialismo. Segundo o brasileiro:

\begin{abstract}
"Não se trata aqui de fazer crítica ideológica a essa concepção oportunista do Estado e da revolução mas, sobretudo de verificar concretamente o caminho pelo qual a classe operária e as mais amplas massas de trabalhadores criaram seus organismos de luta para a tomada do poder no Chile. É muito importante ver como as massas populares mobilizadas no âmbito da Unidade Popular conseguem gerar seus organismos fora dos mecanismos previstos pela estratégia original. Os "cordones industriales", os comitês coordenadores de lutas, os comandos comunais, não somente surgiram fora da institucionalidade em vigor, mas ao mesmo tempo demonstram uma firme vontade de transformá-la. Não é por acaso que os porta-vozes da burguesia se opõem tão radicalmente a esses organismos, mobilizando contra eles as forças armadas e apelando aos preconceitos mais obscurantistas das classes médias. Isso porque, com os seus primeiros passos no sentido da democracia direta, do controle operário da produção, da organização proletária da distribuição, da formação de uma aliança entre as classes exploradas, esses organismos despertam as mais profundas energias revolucionárias do proletariado e abrem uma perspectiva real para a luta pelo poder no Chile. Os reformistas, ao quererem enquadrar esses organismos no interior das instituições estabelecidas, mostram-se incapazes de dirigir o exército mais poderoso das massas populares no enfrentamento social atual". (SADER, 1973).
\end{abstract}

Éder Sader observa no Chile um conjunto de ideias compartilhadas e de experiências políticas vivenciadas de maneira diferente em relação ao Brasil. Menciona a importância da criação popular de organismos que fogem aos limites de sua previsão original, de instituições que surgem fora da institucionalidade. Dá um caráter positivo àquilo que na esfera política da época não poderia ser enquadrado na realidade já estabelecida.

Intelectuais e militantes de Polop e MIR deixaram registros de uma imaginação que identificava no passado as raízes históricas que fatalmente os havia colocado ali. Assumiram seu papel transformador do presente em nome do futuro socialista, que não veio. Suas histórias e memórias, no entanto, até hoje não adquiriram apelo social, não se tornaram fontes para a compreensão da relação que aquele passado continua a manter com os dias de hoje.

No Brasil e no Chile, os golpes de 1964 e 1973, respectivamente, e as ditaduras instauradas, significaram uma ruptura não apenas com o sistema político democrático 
que vigorava, mas com um passado de lutas e projetos radicais. As expectativas de futuro que motivaram aqueles projetos revolucionários também foram eliminadas ao lado de grande parte de seus líderes e movimentos. Crescentes debates acerca daquele mundo que os revolucionários herdaram e partilharam, e da ação que realizaram poderá oferecer novos sentidos e novos começos ao presente.

\section{Referências bibliográficas:}

AGAMBEN, Giorgio. Estado de exceção. São Paulo: Boitempo, 2004.

ARAÚJO, Maria Paula. A Utopia Fragmentada. RJ: FGV, 2000.

FERREIRA, Jorge. João Goulart: uma biografia. Rio de Janeiro: Civilização Brasileira, 2011.

. Leonel Brizola, as esquerdas e a radicalização política no governo Goulart (1961-1964) (s-d). Disponível em http://www.brasa.org/Documents/BRASA_IX/Jorge-Ferreira.pdf (Último acesso em janeiro de 2015)

LISBOA, Apolo Heringer. Cavaleiros sem esperança. IN: Revista de História da

Biblioteca Nacional, Ano 8, Nº0, março de 2013, pp. 31-33.

MARINI, Ruy Mauro. Comentario a Raúl Sendic. In: Cuadernos Políticos, número 41, Ediciones Era, México, julio-diciembre de 1984, pp. 110-112.

MARQUES, Teresa Cristina Schneider. Militância política e solidariedade transnacionais: A trajetória política dos exilados brasileiros no Chile e na França (1968-1979). Tese de Doutorado (Doutorado em ciência política). Programa de Pós Graduação em Ciência Política da Universidade Federal do Rio Grande do Sul. Porto Alegre, 2011.

MIRANDA, Carlos R. Paraguay y la era de Stroessner. Asunción: RP Ediciones (s/d).

MOTTA, Rodrigo Patto Sá. Modernizando a repressão: a USAID e a polícia brasileira.

IN: Revista Brasileira de História Vol.30; N59, São Paulo, junho de 2010.

PAZ, Octavio. O labirinto da solidão e Post-scriptum. Rio de Janeiro: Paz e Terra, $2^{\text {a }}$ Edição, 1984. 
REIS, Daniel Aarão [et al] O golpe e a ditadura militar. 40 anos depois (1964-2004). São Paulo: Edusc, 2004. (Org.) História do Marxismo no Brasil: o impacto das revoluções. Rio de Janeiro: Paz e Terra, 1991, vol.1. ROLLEMBERG, Denise. Exílio. Entre raízes e radares. Rio de Janeiro: Record, 1999. SALES, Jean Rodrigues. O Partido Comunista do Brasil e o Partido Comunista Francês diante da Revolução cubana nos anos 1960. (s-d) Disponível em http://www.hcomparada.historia.ufrj.br/revistahc/artigos/volume001_Num002_artigo00 2.pdf (Último acesso em janeiro de 2015)

SANTOS, Theotonio dos. A Teoria da Dependência. 1. ed. Rio de Janeiro: Editora Civilização Brasileira, 2000.

\section{La Teoria de la Dependencia: Balance y Perspectivas.}

Ciudad de Mexico, México: Plaza y Janés, 2002.

. A teoria da dependência: um balanço histórico e teórico. (s-d).

Disponível em http://www.reggen.org.br/midia/documentos/ateoriadadependencia.pdf (Último acesso em novembro de 2013.

SILVA, Vicente Gil. O papel intervencionista da ditadura civil-militar brasileira na América do Sul. In: História Social, n.18, segundo semestre de 2010.

SIRINELLI, Jean-François. Abrir a História. Novos olhares sobre o século XX francês. Belo Horizonte: Editora Autêntica, 2014.

VITALE, Luis Vitale. Contribución a la Historia del MIR (1965 - 1970). Santiago:

Ed. Instituto de Investigación de Movimientos Sociales "Pedro Vuskovic", 1999.

WASSERMAN, Claudia. América Latina: dependência X desenvolvimento no pensamento marxista. In: ANPUH - XXV SIMPÓSIO NACIONAL DE HISTÓRIA Fortaleza, 2009. Disponível em http://anpuh.org/anais/wp-

content/uploads/mp/pdf/ANPUH.S25.0028.pdf (Último acesso em janeiro de 2015) Sites consultados:

Centro de Estudos Victor Meyer. http://centrovictormeyer.org.br/11-de-setembro-40anos-do-golpe-militar-no-chile/ (Último acesso em fevereiro de 2015) http://www.londres38.cl/1937/w3-channel.html - O site disponibiliza informações sobre a história do local, análises históricas sobre o tema e documentos digitalizados sobre o funcionamento do aparato repressivo chileno. 
http://pulacayo.blogcindario.com/2006/05/00004-la-tesis-de-pulacayo.html http://www.archivochile.com/America_latina/JCR/MLN_T/tupa_de/tupade0001.pdf (último acesso em fevereiro de 2012) www.ucema.edu.ar/ publicaciones/documentos (Último acesso em fevereiro de 2015) http://www.archivochile.com/entrada.html http://www.marini-escritos.unam.mx/index.htm http://www.puntofinal.cl/ http://www.prtargentina.org.ar/documentos/partido/causas_de_la_derrota_del_prt.html http://www1.tau.ac.il/eial/index.php?option=com_content\&task=view\&id=193\&Itemid =159 (último acesso em dezembro de 2012)

http://www.archivochile.com/Archivo_Mir/Doc_Agosto_65_a_67/miragosto65a670001 .pdf Último acesso em janeiro de 2015) 